\title{
Colon cancer cell-derived 12(S)-HETE induces the retraction of cancer-associated fibroblast via MLC2, RHO/ROCK and $\mathrm{Ca}^{2+}$ signalling
}

\author{
Serena Stadler ${ }^{1,2}$ - Chi Huu Nguyen ${ }^{1,3} \cdot$ Helga Schachner $^{1}$ - Daniela Milovanovic ${ }^{1}$ - Silvio Holzner ${ }^{1,2,4}$. \\ Stefan Brenner ${ }^{3} \cdot$ Julia Eichsteininger $^{1,5} \cdot$ Mira Stadler $^{2} \cdot$ Daniel Senfter $^{1,2,4} \cdot$ Liselotte Krenn $^{5}$. \\ Wolfgang M. Schmidt ${ }^{6} \cdot$ Nicole Huttary $^{1} \cdot$ Sigurd Krieger $^{1} \cdot$ Oskar Koperek $^{1} \cdot$ Zsuzsanna Bago-Horvath $^{1}$.

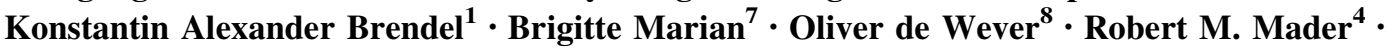 \\ Benedikt Giessrigl $^{1,3} \cdot$ Walter Jäger $^{3} \cdot$ Helmut Dolznig $^{2} \cdot$ Georg Krupitza $^{1}$
}

Received: 22 March 2016/Revised: 6 December 2016/Accepted: 9 December 2016/Published online: 24 December 2016

(C) The Author(s) 2017. This article is published with open access at Springerlink.com

\begin{abstract}
Retraction of mesenchymal stromal cells supports the invasion of colorectal cancer cells (CRC) into the adjacent compartment. CRC-secreted 12(S)-HETE enhances the retraction of cancer-associated fibroblasts (CAFs) and therefore, 12(S)-HETE may enforce invasivity of CRC. Understanding the mechanisms of metastatic CRC is crucial for successful intervention. Therefore, we studied proinvasive contributions of stromal cells in physiologically relevant three-dimensional in vitro assays consisting of CRC spheroids, CAFs, extracellular matrix and endothelial cells, as well as in reductionist models. In order to elucidate how CAFs support CRC invasion, tumour spheroid-induced CAF retraction and free intracellular $\mathrm{Ca}^{2+}$ levels were measured and pharmacological- or siRNA-based inhibition of selected signalling cascades was performed. CRC spheroids caused the retraction of CAFs, generating entry gates in the adjacent surrogate stroma. The responsible trigger factor 12(S)-HETE provoked a signal, which
\end{abstract}

Electronic supplementary material The online version of this article (doi:10.1007/s00018-016-2441-5) contains supplementary material, which is available to authorized users.

\section{Georg Krupitza}

georg.krupitza@meduniwien.ac.at

1 Clinical Institute of Pathology, Medical University of Vienna, Waehringer Guertel 18-20, 1090 Vienna, Austria

2 Institute of Medical Genetics, Medical University of Vienna, Waehringer Strasse 10, 1090 Vienna, Austria

3 Department for Clinical Pharmacy and Diagnostics, Faculty of Life Sciences, University of Vienna, Althanstrasse 14, 1090 Vienna, Austria

4 Department of Medicine I, Comprehensive Cancer Centre, Medical University of Vienna, Waehringer Guertel 18-20, 1090 Vienna, Austria was transduced by PLC, IP3, free intracellular $\mathrm{Ca}^{2+}, \mathrm{Ca}^{2+}$ calmodulin-kinase-II, RHO/ROCK and MYLK which led to the activation of myosin light chain 2 , and subsequent CAF mobility. RHO activity was observed downstream as well as upstream of $\mathrm{Ca}^{2+}$ release. Thus, $\mathrm{Ca}^{2+}$ signalling served as central signal amplifier. Treatment with the FDAapproved drugs carbamazepine, cinnarizine, nifedipine and bepridil $\mathrm{HCl}$, which reportedly interfere with cellular calcium availability, inhibited CAF-retraction. The elucidation of signalling pathways and identification of approved inhibitory drugs warrant development of intervention strategies targeting tumour-stroma interaction.

Keywords 3D invasion model - Tumour progression . ECM $\cdot$ Arachidonic acid metabolite $\cdot$ Signal transduction

Abbreviations

ALOX12/15 Lipoxygenase 12/15

BAPTA-AM 1,2-Bis(2-aminophenoxy)ethane-

$N, N, N$, $N$ '-tetraacetic

acid

tetrakis(acetoxymethyl ester)

5 Department of Pharmacognosy, Faculty of Life Sciences, University of Vienna, Althanstrasse 14, 1090 Vienna, Austria

6 Neuromuscular Research Department, Centre of Anatomy and Cell Biology, Medical University of Vienna, Waehringer Strasse 13, 1090 Vienna, Austria

7 Department of Medicine I, Institute of Cancer Research and Comprehensive Cancer Centre, Medical University of Vienna, Borschkegasse 8a, 1090 Vienna, Austria

8 Department of Radiation Oncology and Experimental Cancer Research, Ghent University, De Pintelaan 185, 9000 Ghent, Belgium 


$\begin{array}{ll}\text { BEC } & \text { Blood endothelial cell } \\ \text { CamK-II } & \begin{array}{l}\mathrm{Ca}^{2+} \text {-calmodulin kinase II } \\ \text { CRC }\end{array} \\ \text { Colorectal cancer } \\ \text { CCID } & \text { Circular chemorepellent-induced defect } \\ \text { CAF } & \text { Cancer-associated fibroblast } \\ \text { EC } & \text { Endothelial cell } \\ \text { HLF } & \text { Human lung fibroblast } \\ \text { IP3 } & \text { Inositol-3-phosphate } \\ \text { MLC2 } & \text { Myosin light chain 2 } \\ \text { MMP1 } & \text { Matrix metallo-protease 1 } \\ \text { MYLK } & \text { Myosin light chain kinase } \\ \text { PLC } & \text { Phospholipase C } \\ \text { RHO } & \text { Ras homologue gene family member } \\ \text { ROCK } & \text { Rho-associated protein kinase } \\ \text { SiRNA } & \text { Small interfering RNA } \\ \text { 3D } & \text { 3-Dimensional } \\ \text { 12(S)-HETE } & \text { 12(S) hydroxyeicosatetraenoic acid }\end{array}$

\section{Introduction}

The risk to develop colorectal cancer (CRC) is high and the danger to die from metastases is evident. The multistage nature of CRC development [1,2] defines a number of tumour suppressor genes and (proto)-oncogenes that become de-regulated (i.e. by mutations, epigenetic modulation of gene expression, or other), and once gene expression changes in a certain spatio-temporal order the cancer progresses stepwise in the well-known sequence: aberrant crypt foci-adenoma-primary cancer-metastasising carcinoma with the tumour leaving the hitherto defined area. The vast mechanistic complexity of metastatic spreading involves the dissolution of the basement membrane, invasion into the surrounding stroma, intravasation into blood and lymphatic vessels, circulation and survival in these vessels, extravasation and eventually colonialisation of a distant secondary site. The tumourstroma is critically involved in these processes and there is compelling evidence for a cancer-associated fibroblast (CAF) gene signature as adverse prognostic marker in CRC $[3,4]$. Thus, CRC needs the cooperation of stromal cells to facilitate metastatic dissemination, yet the mechanisms are poorly understood. A suspect pro-metastatic factor, which is secreted by tumour cells and that takes on control over stromal endothelial cells, is 12(S)-HETE. This pro-inflammatory arachidonic acid metabolite perturbs intercellular junctions [5] and causes the retraction of lymphatic and blood endothelial cell walls. Therefore, 12(S)-HETE is called "endothelial retraction factor" [6] and may facilitate CRC intravasation and lymph node metastasis [7]. Further, 12(S)-HETE, which is metabolised by the lipoxygenases ALOX12 and ALOX15 [8] and by cytochrome-P450-1A1 (CYP1A1) [9, 10], induces the metastatic spreading of prostate carcinoma cells [11]. 12(S)-HETE levels are not significantly different in the tissue specimen of normal, polyp and cancer mucosa [12], which is in accordance with similar ALOX12 expression in normal glandular colon cells and CRC tissue as detected by immunohistochemistry (http://www.proteinatlas.org). However, the CRC cell lines Caco2, SW480 and SW620 express steadily increasing levels of ALOX12 and secrete increasing amounts of 12(S)-HETE, respectively, and this is directly proportional to their metastasising potential i.e. increased growth in soft agar and enhanced migration [13]. In line with this observation, CYP1A1 mRNA is over-expressed in CRC liver metastases as compared to normal colonic epithelium, as detected by RNASeq, whereas CYP1A1 mRNA and protein expression does not vary, between normal colonic tissue and CRC. Hence, there may exist a direct correlation between 12(S)-HETE production and metastatic spreading. This is further supported by the finding that 12(S)-HETE activates the pro-metastatic transcription factor ZEB1 in endothelial cells, assisting the formation of cancer spheroid-triggered "circular chemorepellent induced defects" (CCIDs) [14], which resemble entry gates for the tumour into the vasculature [15]. Conversely, the inhibition of ZEB family expression by miR200 in endothelial cells reduces their potential to form CCIDs [7]. Taken together there is ample evidence that 12(S)-HETE and the ZEB pathway contribute to malignancy and therefore, studying the interface between cancer cells and their immediate stromal environment is relevant to understand tumour spreading.

In the lymph node metastases of breast cancer patients, the production of 12(S)-HETE correlates directly with increased ALOX15 expression and inversely with metastasis-free survival. Moreover, high ALOX12 expression in the lymph node metastases of breast cancer patients inversely correlates with metastasis-free survival as well [15]. The contribution of ALOX15 to lymph node metastases was furthermore proven in SCID mice, which were orthotopically transgrafted with MCF-7 cells in which ALOX15 [the major 12(S)-HETE producing enzyme in this cell line] was knocked-down [15].

Physiologically, neutrophils and activated macrophages secrete 12(S)-HETE, which causes endothelial barrier retraction and enables their transmigration through the vasculature to reach sites of inflammation [5, 16]. Apparently, cancer cells can co-opt this property as cancer cellsecreted 12(S)-HETE activates MLC2 in lymph endothelial cells as a prerequisite for endothelial junction retraction and formation of CCIDs [5, 17-19].

Here, we highlighted the role of 12(S)-HETE and the response of CAFs in this inter-cellular communication and tried to adapt a 3D intravasation model, to study mechanisms of 12(S)-HETE-triggered CRC spheroid invasion into the CAF compartment. We demonstrate that CAFs 
retract from CRC cell spheroids and form CCIDs and identified signalling pathways that steer this process.

\section{Materials and methods}

\section{Antibodies and reagents}

Polyclonal rabbit anti-phospho-myosin light chain 2 (Ser19) and polyclonal rabbit anti-myosin light chain 2 were purchased from Cell Signaling (Danvers, MA, USA), monoclonal mouse anti-MYLK was from Santa Cruz Biotechnology (Heidelberg, Germany), polyclonal rabbit anti-BLT2 antibody was from Sigma (Munich, Germany), polyclonal rabbit anti-12(L)-HETE antibody (L-configuration is identical to S-configuration for 12-HETE) from Enzo Life Sciences (Lausen, Switzerland), monoclonal mouse anti-cytokeratin-20 (CK20) antibody from Neomarker (Thermo Fisher Scientific, Inc., Waltham, MA, USA), monoclonal mouse anti-tenascin $\mathrm{C}$ antibody from Novocastra (Thermo Fisher Scientific, Inc., Waltham, MA, USA), and polyclonal rabbit anti-GAPDH was from Trevigen (Gaithersburg, MD, USA). Polyclonal swine anti-rabbit IgG was purchased from Dako (Glostrup, Denmark) and polyclonal Alexa 488 goat anti-mouse and Alexa 594 goat antirabbit antibodies were purchased from Molecular Probes (Thermo Fisher Scientific, Inc., Waltham, MA, USA).

siRNAs targeting MLC2 (MYL2; SMART pool, ONTARGET PLUS, Cat. No.: L-011087000005) and MYLK (SMART pool, ON-TARGET PLUS, Cat. No.: L-0053510000) were ordered from Dharmacon (Gene Expression and Gene Editing, GE Healthcare, Lafayette, CO, USA), and non-targeting control siRNA (Silencer Select Negative Control No. 1 siRNA, Cat. No.: 4390843) was from Ambion (Life Technologies, Carlsbad, CA, USA).

Baicalein, BAPTA-AM, edelfosine, KN-62 and Y27632 were purchased from Sigma Aldrich (Munich, Germany), blebbistatin, U73122 and rhosin were from Calbiochem (Merck Millipore, Darmstadt, Germany), bepridil hydrochloride (B5016), cinnarizine (C5270), carbamazepine (C8981) and nifedipine (N7634) from Sigma Aldrich (Munich, Germany). 12(S)-HETE was purchased from Cayman Chemical (Ann Arbor, MI, USA), and celltracker Green CMFDA Dye and cell-tracker Red CMTPX Dye were ordered from Invitrogen (Karlsruhe, Germany).

\section{Cell culture}

Human SW620 (CCL-227, lymph node metastasis) and SW480 (CCL-228, primary tumour) colorectal adenocarcinoma cells were obtained from American Type Culture Collection (ATCC, Rockville, MD, USA) and grown in
RPMI or DMEM, respectively, supplemented with $10 \%$ foetal calf serum (FCS), $1 \%$ penicillin/streptomycin (PS), and L-glutamine. Human colon adenoma cells, LT-97 [20], were cultivated in WNRE medium [RPMI/10\% FCS supplemented with conditioned medium of $\mathrm{L}$ cells producing recombinant WNT3A, Noggin and R-spondin (10\% each) supplemented with human recombinant EGF $(50 \mathrm{ng} / \mathrm{ml}$, PeproRech)]. Human Lung Fibroblasts (HLFs, CCL-135) were purchased from American Type Culture Collection (ATCC, Rockville, MD, USA) and maintained in DMEM supplemented with $10 \%$ FCS, $1 \%$ PS and $1 \%$ L-glutamine. Human primary CAF (CT5.3) were isolated from a colorectal adenocarcinoma resection specimen obtained in accordance with the local ethics committee (Ghent University Hospital). In short, tissue fragments were cut in small pieces and transferred into a six-well plate with FCS. Isolated CT5.3 were infected with a pBABE retroviral vector expressing the hTERT open reading frame [21].

CT5.3 cells were cultivated in DMEM supplemented with $10 \%$ FCS, $1 \%$ PS, and $1 \%$ L-glutamine and $2 \mu \mathrm{g} / \mathrm{ml}$ puromycin. Primary CAFs (CAF3) [22] and human dermal microvascular endothelial cells (BECs; C-12260, Promocell, Heidelberg, Germany) were maintained in EGM2 MV (Clonetics CC-4147, Allendale, NJ, USA). All cells were kept at $37{ }^{\circ} \mathrm{C}$ in a humidified atmosphere containing $5 \%$ $\mathrm{CO}_{2}$.

\section{Spheroid formation}

SW480 cells ( 1500 cells per spheroid) or SW620 cells (2000 cells per spheroid) were transferred into DMEM (supplemented with 5\% FCS, 1\% PS and 1\% L-glutamine) containing methylcellulose (M-512; Sigma Aldrich) at a final concentration of $0.3 \% .150 \mu \mathrm{l}$ of this cell suspension was transferred to each well of a 96-well round bottom plate (Greiner Bio-one, Cellstar 650185, Kremsmünster, Austria). The plates were centrifuged for $30 \mathrm{~min}$ at $1000 \mathrm{rpm}$ and thereafter incubated for 4 days to allow spheroid formation.

LT-97 cells (2000 cells per spheroid) were transferred into WNRE medium without methylcellulose and $150 \mu \mathrm{l}$ of this cell suspension seeded into each well of a 96-well, non-adhesive, round bottom plate (Nunclon Sphera ULA plates). The plates were centrifuged for $30 \mathrm{~min}$ at $1000 \mathrm{rpm}$ and thereafter incubated for 4 days to allow spheroid formation.

\section{Colon cancer invasion model (collagen gel culture)}

Nylon meshes were prepared from nylon mesh inserts of Medicon syringe filters (100 $\mu \mathrm{m}$, Becton-Dickinson) of which a hole of $1 \mathrm{~cm}$ diameter was cut out in the centre. The nylon meshes were autoclaved and placed onto the inside surface of lids of 24 -well plates. CT5.3 cells were 
stained with cell-tracker green (Invitrogen, Karlsruhe, Germany), trypsinised and counted. A total of $4 \times 10^{5}$ cells for each gel were transferred into 1.5-ml Eppendorf tubes and centrifuged at $1000 \mathrm{rpm}$ for $5 \mathrm{~min}$ at $4{ }^{\circ} \mathrm{C}$. For collagen gel preparation, all steps were performed on ice. Collagen solutions were prepared by mixing $2 \mathrm{mg} / \mathrm{ml}$ collagen I (Corning, collagen I, rat tail, Bedford, MA, USA), $10 \% 10 \times$ PBS and DMEM and were neutralised by the addition of $7 \mu \mathrm{l} / \mathrm{ml} 1 \mathrm{M} \mathrm{NaOH}$. A total of $300 \mu \mathrm{l}$ each of the collagen solution was transferred into the tubes containing the cell pellets which were gently re-suspended. The collagen/cell suspensions were carefully transferred on the nylon meshes and incubated for $30 \mathrm{~min}$ at $37{ }^{\circ} \mathrm{C} / 5 \%$ $\mathrm{CO}_{2}$ to allow the collagen solutions to solidify. Thereafter, $1 \mathrm{ml}$ DMEM was added into each well and gels were incubated for $24 \mathrm{~h}$. Then, BECs were stained with celltracker red, trypsinised and counted. $2 \times 10^{5}$ cells were transferred on top of each collagen gel and the co-cultures were incubated for another $24 \mathrm{~h}$. SW620 spheroids were prepared as described above, washed and carefully placed on top of the BEC monolayer. $24 \mathrm{~h}$ after spheroid transfer, CCID areas in BECs and CAFs were analysed using a fluorescence microscope.

\section{Circular chemo-repellent-induced defect (CCID) assay}

In this assay, the sizes of cell free areas (circular chemorepellent induced defects; CCIDs) which are formed in the CAF monolayer directly underneath the tumour spheroids were measured. Primary CAFs, CT5.3 cells or HLFs were grown to confluence in 24-well plates and subsequently stained with cell-tracker green. Colon cancer spheroids were washed with PBS and transferred on top of the CAF or HLF monolayers. After $6 \mathrm{~h}$ of co-cultivation, CCID areas were photographed using an Axiovert (Zeiss, Jena, Germany) fluorescence microscope to visualise the celltracker stained CAFs or HLFs. CCID areas were calculated using Zen Little 2012 software (Zeiss, Jena, Germany). For each condition, the CCID areas of at least 15 spheroids were measured.

\section{Transfection of primary CAFs and CT5.3 cells}

Cells were seeded in 24-well plates and grown to $70 \%$ confluence. A total of $0.75 \mu \mathrm{g}$ siRNA and $4 \mu \mathrm{l} \mathrm{HiPerFect}$ Transfection Reagent (QIAGEN, Cat. No.: 301705) were mixed in $100 \mu \mathrm{l}$ serum-free medium and incubated for $30 \mathrm{~min}$ at room temperature to allow the formation of transfection complexes, which were then carefully added onto the cells (to a final siRNA concentration of $100 \mathrm{nM}$ ). The cells were incubated for $48 \mathrm{~h}$ at normal growth conditions and were subsequently used for CCID assays or RNA isolation.

\section{Quantitative RT-PCR (qPCR)}

Cells were harvested after transfection, and RNA was isolated using the RNeasy Mini Kit 50 and QIAshredder 50 (QUIAGEN, Hamburg, Germany). The final RNA concentration was measured using a NanoDrop Fluorospectrometer (Thermo Fisher Scientific, Inc., Waltham, MA, USA). An amount of $2 \mu \mathrm{g}$ of total RNA was reverse transcribed using RNA to cDNA EcoDry Premix Protocol-At-A-Glance (Clontech, 2 Saint-Germain-enLaye, France). The resulting cDNA was amplified using TaqMan Gene Expression Master Mix (Applied Biosystems, Vienna, Austria). The PCR products were analysed on the Chromo4 PCR System (Bio-Rad, Hercules, CA, USA). The following TagMan probes were used: GAPDH (Hs99999905_m1) and MYLK (Hs00364926_ma). qPCR was performed in triplicate for each cDNA template. Gene expression was normalised to GAPDH expression (glyceraldehyde 3-phosphate dehydrogenase) and was calculated using the $\Delta \Delta C_{\mathrm{T}}$ method.

\section{SDS gel electrophoresis and Western blotting}

CT5.3 cells were grown in T-25 tissue culture flasks (Nunc, Roskilde, Denmark) or six-well plates to $80 \%$ confluence and subsequently starved for $24 \mathrm{~h}$. Then, cells were pretreated with respective inhibitors or solvent for $1 \mathrm{~h}$ and stimulated with $1 \mu \mathrm{M}$ 12(S)-HETE for another $15 \mathrm{~min}$. Afterwards, cells were washed twice with ice-cold PBS and lysed in buffer containing $50 \mathrm{mM}$ Tris- $\mathrm{HCl}$ (pH 6.8), 6\% SDS, $20 \%$ glycerine, $1.85 \mathrm{mM}$ EDTA, phosphatase inhibitor cocktail, and protease inhibitor cocktail. For complete cell lysis, the mixture was sonicated 5-10 times on ice. The lysate was stored at $-20{ }^{\circ} \mathrm{C}$ until further analysis. Equal amounts of protein were separated by SDS polyacrylamide gel electrophoresis and electro-transferred onto Amersham Hybond-P PVDF transfer membrane (GE Healthcare, Freiburg, Germany) at $100 \mathrm{~V}$ for $1 \mathrm{~h}$ in ice-cold transfer buffer [containing $20 \mathrm{mM}$ Tris-base, $150 \mathrm{mM}$ glycine, $20 \%$ (v/v) methanol, $\mathrm{pH}$ 8.5]. Membranes were stained with Ponceau S (Sigma-Aldrich, Munich, Germany) to control transfer efficiency and equal sample loading. After washing with TBS-T (Tris Buffered Saline/Tween 20; pH 7.6), membranes were immersed in blocking solution (5\% non-fat dry milk in TBS containing $0.1 \%$ Tween20) at room temperature for $1 \mathrm{~h}$. Then, membranes were washed and incubated with primary antibodies (5\% BSA in TBS-T; 1:500-1:1000) by gently rocking at $4{ }^{\circ} \mathrm{C}$ overnight. Thereafter, membranes were washed and incubated with 
secondary antibodies (peroxidase-conjugated swine antirabbit IgG, dilution 1:5000) at room temperature for $1 \mathrm{~h}$. Chemo-luminescence was developed by Amersham ECL prime Kit (GE Healthcare, Freiburg, Germany) and detected using a Lumi-Imager F1 Workstation (Roche, Basel, Switzerland). Densitometry of Western blots was analysed with Image-J software (National Institutes of Health, Maryland, USA).

\section{Immunofluorescence}

Fresh unfixed human tissue was stored in nitrogen and sectioned in 3- $\mu \mathrm{m}$-thick slices using a Cryostar NX50 (Thermo Fisher Scientific, Inc., Waltham, MA, USA). Sections were then transferred on Superfrost-Plus object slides (Thermo Fisher Scientific, Inc., Waltham, MA, USA) and dried for $10 \mathrm{~min}$ at room temperature (RT). Then samples were incubated with primary antibodies (1:50 in Tris buffer $\mathrm{pH}$ 7.2) for $30 \mathrm{~min}$ at RT. After washing three times with Tris buffer, samples were incubated with secondary antibodies for another $30 \mathrm{~min}$ at RT. Then, slides were washed again and incubated with DAPI $(1: 50,000)$ for $1 \mathrm{~min}$. Thereafter, samples were embedded with GelTol, coverslipped and analysed on a Zeiss LSM5Exiter confocal microscope (Zeiss, Jena, Germany). Surgical specimens were collected from three patients who underwent surgery for colorectal cancer and gave their informed consent. The study protocol was approved by the ethics committee of the Medical University of Vienna (EK 1659/2012).

\section{Intracellular $\mathrm{Ca}^{2+}$ assay}

Free intracellular $\mathrm{Ca}^{2+}$ levels were measured using FluoForte Calcium Assay Kit (Enzo Life Science, Ann Abor, MI, USA). $3 \times 10^{4}$ CT5.3 cells/well/100 $\mu$ l DMEM were seeded into 96-well black-wall clear-bottom plates (Nunc, Thermo Scientific, NY, USA). After $24 \mathrm{~h}$, cells were pretreated with respective inhibitors or solvent for $1 \mathrm{~h}$ and subsequently incubated in $100 \mu \mathrm{l}$ FluoForte Dye for $45 \mathrm{~min}$ at $37{ }^{\circ} \mathrm{C}$ and $15 \mathrm{~min}$ at room temperature. Then, cells were stimulated with $1 \mu \mathrm{M} 12$ (S)-HETE and fluorescence was measured at 490/525 $\mathrm{nm}$ using a fluorescence plate reader.

\section{2(S)-HETE assay}

DLD-1 and SW620 cells were seed in six-well plates and grown in $2.5 \mathrm{ml}$ complete MEM medium to $\sim 70-80$ confluence when FCS was removed overnight. Then, cells were treated with $10 \mu \mathrm{M}$ arachidonic acid (Sigma-Aldrich, Munich, Germany) in serum-free medium for another $4 \mathrm{~h}$. The concentration of 12(S)-HETE in the cellular supernatant was measured with minor modifications as described previously [23] using the 12(S)-HETE enzyme immunoassay kit (Enzo Life Sciences, Lausen, Switzerland). Absorbance was measured with a Wallac 1420 Victor 2 multilabel plate reader (Perkin Elmer Life and Analytical Sciences, Shelton, CT, USA). The concentration of 12(S)-HETE in the cellular supernatant was normalsed to cell number to account for differences in the cell number.

\section{Statistical analysis}

For statistical analyses, Excel 2013 software and Prism 6 software package (GraphPad, San Diego, CA, USA) were used. The values were expressed as mean \pm SEM and oneway ANOVA and student's $t$ test was applied to compare differences between control samples and treatment groups. Statistical significance level was set to $p<0.05$.

\section{Results}

\section{Establishment of a 3D in vitro model resembling CRC invasion into stroma}

It was shown that cancer cells repel endothelial cells [15], and here we investigated whether fibroblasts may as well retract from CRC spheroids. SW620 spheroids were placed on top of immortalised CT5.3 CAFs [21], which induced their retraction within $6 \mathrm{~h}$ thereby forming CCIDs (Fig. 1a). In patients, the stroma around CRC mucosa often consists of densely packed fibroblasts. Therefore, CT5.3 $\mathrm{CAFs}$ were cultivated more densely and also under these conditions CAFs were forced by SW620 spheroids to retract, although the CCID areas were smaller than in less densely grown CAFs (Fig. 1b; in order to better distinguish individual fibroblasts in this setting $50 \%$ of CT5.3 were stained with cell-tracker red and 50\% with cell-tracker green). Also, primary CAFs (CAF3) [22] responded with retraction when SW620 spheroids were placed on top (Fig. 1c). Furthermore, SW480 spheroids (SW480 is the primary tumour of the matching SW620 lymph node metastasis)-induced CCIDs in CT5.3 cell layers, which demonstrates the potential also of the primary tumour to invade the surrounding stroma (Fig. 1d). In contrary, noncancerous LT-97 adenoma cells [20] did not trigger CCID formation in the CAF barrier within $6 \mathrm{~h}$ (Fig. 1d). To stress the model further, CAFs were covered with collagen I, which mimics the stroma/matrix histopathology surrounding CRCs. Then, SW620 spheroids were placed on top, which still caused the retraction of CT5.3 cells thereby establishing a cell-free area (not shown). In addition, blood endothelial cells (BECs) were included to this model and 
hours of spheroid/fibroblast confrontation
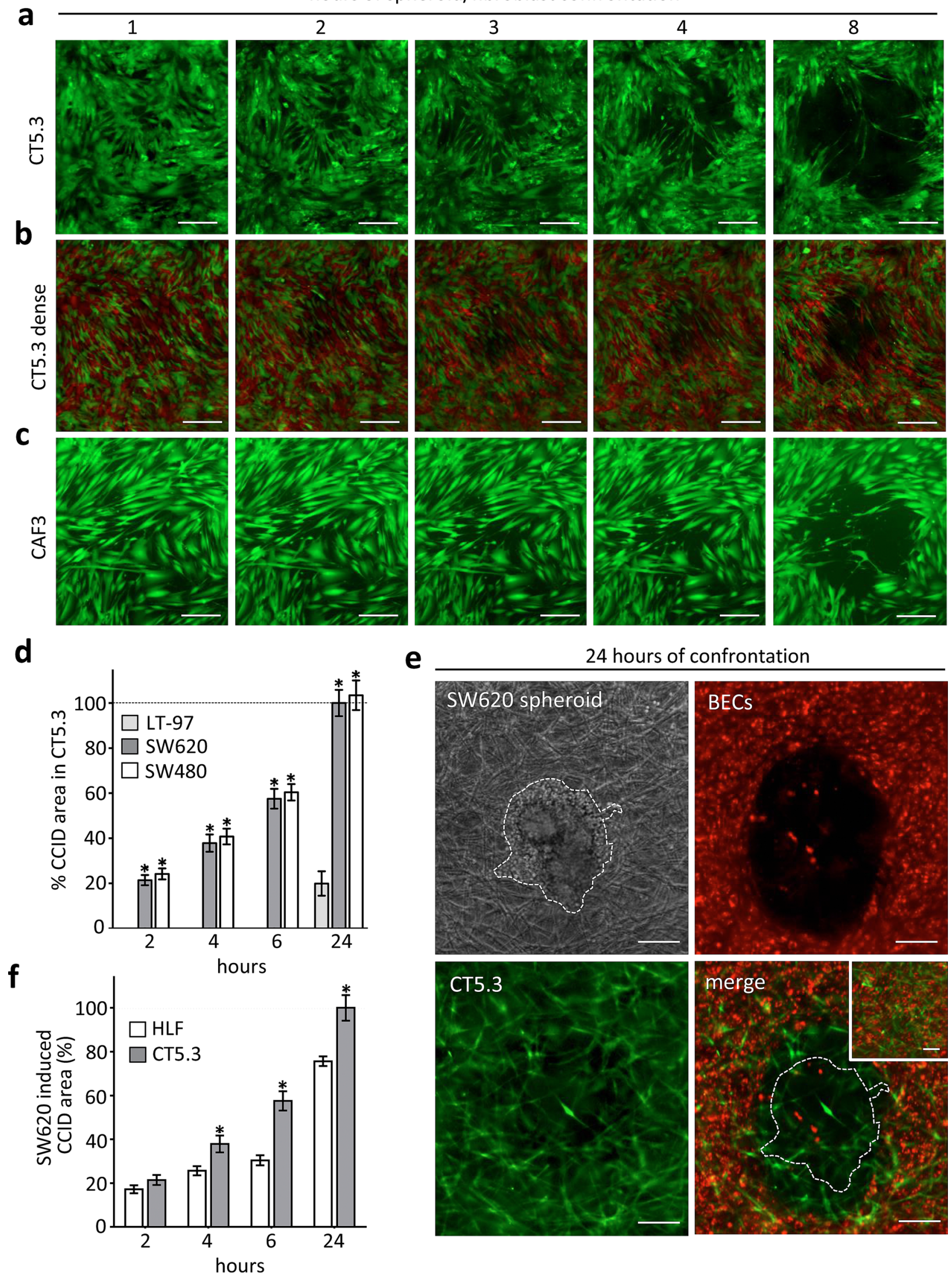
4Fig. 1 Colon cancer spheroid-induced CCID formation in CAFs SW620 spheroids was transferred on a cell-tracker (green) stained CT5.3 or b more densely seeded CT5.3 (50\% of CT5.3 were stained with green cell-tracker the other $50 \%$ were stained with red celltracker) or $\mathbf{c}$ on cell-tracker (green) stained primary CAF3 layers. The formation of CCIDs was monitored at different time points by fluorescence microscopy. The formation of CCIDs was monitored at different time points by fluorescence microscopy. Representative pictures of at least three independent experiments are shown. d Quantification of SW620, SW480 and LT-97 induced CCID formation in CT5.3 monolayers. e Collagen gel culture of CT5.3 cells, BECs and SW620 spheroids. Cell-tracker (green) stained CT5.3 cells were embedded in collagen I gel. Then, cell-tracker (red) stained BECs were seeded on top of these gels. Subsequently, SW620 spheroids were placed on top and the formation of CCIDs was monitored after $24 \mathrm{~h}$ by fluorescence microscopy. Cultures without SW620 spheroids were used as controls (small inset). f Quantification of SW620 spheroid-induced CCID formation in CT5.3 and HLF monolayers. Scale bars $200 \mu \mathrm{m}$. Bar graphs represent means, error bars indicate \pm SEM, asterisks significance compared to control $(p<0.05 ; t$ test or ANOVA)

seeded onto the surface of collagen I-embedded CAFs. On top of this co-culture system, SW620 spheroids were placed. Under these conditions, the spheroids induced the formation of CCIDs in BECs and also the retraction of the subjacent fibroblasts (Fig. 1e). The setting of this in vitro model closely resembles the patho-physiology in humans when CRC cells extravasate the blood vasculature and invade a distant organ. Metastatic CRC especially invades liver and lungs. Indeed, SW620 spheroids caused also the retraction of normal human lung fibroblasts (HLFs) even if these cells were less responsive when compared with CAFs (Fig. 1f). Therefore, the phenomenon of CCID formation is not restricted to colon CAFs as also EC junction retraction was due to CRC-secreted 12(S)-HETE [7]. To localise 12(S)-HETE in human normal and cancerous colonic epithelia, fresh cryo-preserved and non-fixed tumour tissues were analysed by immunofluorescence and laser scanning microscopy. In normal as well as in cancerous colonic mucosa cells, 12(S)-HETE was detected (Supplementary Fig. S1). A quantification by this method was not possible, as the harsh conditions of the colon environment certainly degraded most of the 12(S)-HETE molecule (which is rapidly oxidised at four different double bonds etc.), but in general, these data are in agreement with HPLC data, which demonstrate that normal colon-, polypand colon cancer mucosa produce similar amounts of 12(S)-HETE [12]. The level of the 12(S)-HETE concentration in metastases of CRC remains unexplored, since metastases are not surgically removed in the clinical routine. To this end, it is of particular interest that RNA sequencing revealed CYP1A1 mRNA over-expression in CRC liver metastases as compared to normal colonic epithelium (http://www.ebi.ac.uk/gxa/experiments/EGEOD-50760? geneQuery=ENSG00000140465\&query FactorValues=g2_g1\&_specific $=$ on $)$.
Given that CCID formation was demonstrated in all variations of our experiments and that 12(S)-HETE was detected in CRC tissue, the model was reduced in the next step (as shown in Fig. 1a, c) to investigate the underlying mechanism causing retraction.

\section{2(S)-HETE-activated MLC2 triggers CCID formation in the CRC-stroma invasion model}

Metastatic SW620 cells were shown to express ALOX12 and to secrete 12(S)-HETE. SW480 and the well-differentiated $\mathrm{CaCo} 2$ cells (both derived from primary tumour sites) express less ALOX12 and produce only half the amount of 12(S)-HETE as compared to SW620 cells [13]. Also, DLD-1 cells (derived from a primary tumour site) secreted lower levels of 12(S)-HETE [7.3 ng/ml (23 nM)] than metastatic SW620 cells $[10.6 \mathrm{ng} / \mathrm{ml}(33 \mathrm{nM})]$ within $4 \mathrm{~h}\left(1 \times 10^{6}\right.$ cells, each). This suggests a direct correlation between higher 12(S)-HETE production and increasing malignancy. However, this did not correlate with their CCID-forming potential, as SW60 and SW480 spheroids induced CCID formation alike (Fig. 1d) and this implicated that both cell types may have produced an overload of 12(S)-HETE, which triggered maximal fibroblasts retraction. In the immediate proximity of CAFs, the concentration of 12(S)-HETE that was secreted by SW620 spheroids must have been much higher than $33 \mathrm{nM}$ at least in the in vitro setting studied here. To confirm the contribution of 12(S)-HETE upon SW620 spheroid-triggered CCID formation within the CAF barrier, ALOX12, a major producer of 12(S)-HETE, was inhibited by baicalein. In the CRC/CAF invasion model using immortalised CT5.3 fibroblasts as well as primary CAF3, baicalein attenuated the formation of CCIDs (Fig. 2a, b). Therefore, ALOX12 in SW620 cells, and consequently 12(S)-HETE, induced CCID formation in CAF barriers similar to that induced in EC barriers [7]. EC retraction and CCID formation depend on the expression and activity of the mobility marker myosin light chain 2 (MLC2) [24] and we hypothesised that this might also be the case in CAFs. Indeed, the treatment of CT5.3 cells with $0.25-2.0 \mu \mathrm{M}(80-638 \mathrm{ng} / \mathrm{ml})$ 12(S)-HETE triggered the phosphorylation of MLC2 at serine 19, indicating its activation (Fig. 2c). Therefore, CAFs were further on treated with a standardised concentration of $1 \mu \mathrm{M} 12$ (S)-HETE to study the mechanisms of their retraction and CCID formation. MLC2 was essential for CAF retraction, since siRNA-mediated knock-down of MLC2 expression (siMLC2) reduced the CCID areas (Fig. 2d; proper knock-down of MLC2 is shown in supplementary Fig. S2). Inhibition of MLC2 activity by blebbistatin (Fig. 2e) significantly inhibited CCID formation in the CAF barrier as well, which further substantiated the contribution of MLC2 to CAF retraction. 
12(S)-HETE-triggered $\mathrm{Ca}^{2+}$ release induces MLC2 activation and CCID formation

12(S)-HETE induces $\mathrm{Ca}^{2+}$ release in normal human fibroblasts [25], HEK239 cells [26] and in CHO cells through the BLT2 low affinity receptor [27], and was reported to activate L-type calcium channels in renal myocytes [28]. BLT2 is expressed in the colon cancerassociated fibroblasts, CT5.3, as well (Supplementary Fig. S3) and accordingly, $\mathrm{Ca}^{2+}$ levels increased
Fig. 2 CCID formation in CT5.3 and CAF3 is inhibited by baicalein and depends on MLC2. SW620 spheroids were pre-treated with baicalein at indicated concentrations or solvent (control; DMSO) and transferred on cell-tracker stained a CT5.3 or b CAF3 monolayers. After $6 \mathrm{~h}$ CCID areas were measured. c CT5.3 cells were stimulated with 0.25 , $0.5,1.0,1.5$ and $2.0 \mu \mathrm{M} 12(\mathrm{~S})-$ HETE or solvent (0) for $20 \mathrm{~min}$. Western blotting was used to determine MLC2

phosphorylation at serine 19 .

Equal sample loading was controlled by MLC2 total protein and GAPDH. PhosphoMLC2 (p-MLC2) was

quantified by densitometry and normalised to MLC2 and

GAPDH. Solvent treated control was set to 1 . d CT5.3 cells were transfected with either nontargeting RNA (NTC) or siRNA targeting MLC2 (siMLC2). After 24 h SW620 spheroids were transferred on top of the CT5.3 monolayers and after $6 \mathrm{~h}$ co-cultivation CCID areas were measured. e CT5.3 cells were pre-treated with blebbistatin at indicated concentrations or solvent control (control; DMSO). Then, SW620 spheroids were placed on top of the CT5.3 cell monolayers for $6 \mathrm{~h}$ and CCID areas were measured. Bar graphs represent means, error bars indicate \pm SEM, asterisks significance compared to control $(p<0.05$; $t$ test)
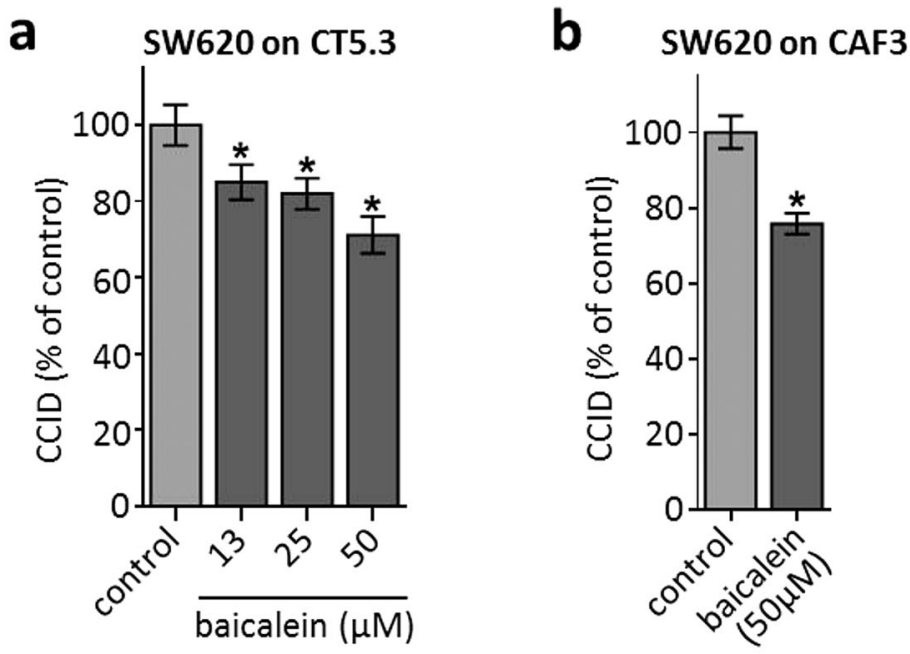

C
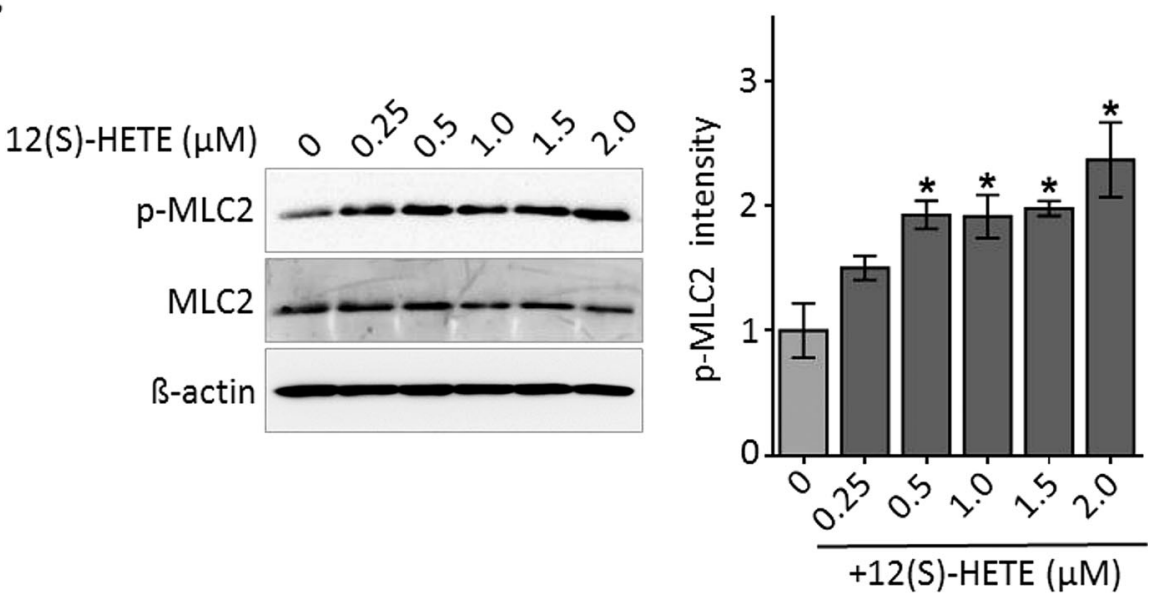

d

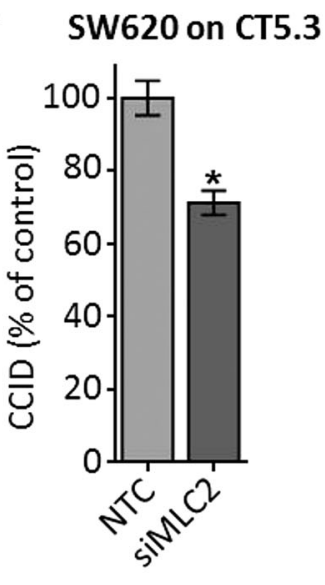

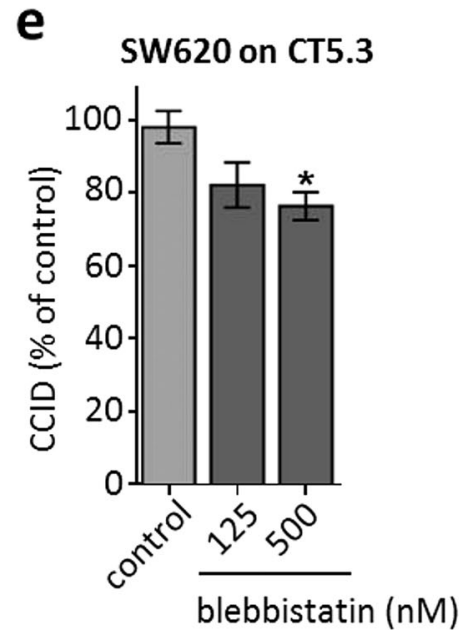


significantly in 12(S)-HETE-treated CT5.3 cells (Fig. 3a). The co-treatment with the specific intracellular $\mathrm{Ca}^{2+}$ chelator BAPTA-AM evidenced that $\mathrm{Ca}^{2+}$ signalling was responsible for 12(S)-HETE-induced Ser19-MLC2 phosphorylation (Fig. 3b) and furthermore, BAPTA-AM inhibited CRC-induced CCID formation in CT5.3 (Fig. 3c) and CAF3 (Fig. 3d). The immediate upstream factor triggering $\mathrm{Ca}^{2+}$ release from intracellular stores is inositol-3phosphate (IP3) and the IP3-generating enzyme phospholipase-C-beta (PLC $\beta$ ). Consistently, the inhibition of IP3 generation by $\mathrm{U} 73122$ significantly attenuated $\mathrm{Ca}^{2+}$ release (Fig. 3e) and CRC-triggered CCID formation (Fig. 3f) and the PLC inhibitor edelfosine attenuated the retraction of CT5.3 cells as well (Fig. 3g). In addition, both inhibitors, U73122 and edelfosine, inhibited the phosphorylation of MLC2 (Supplementary Fig. S4). Therefore, the PLC $\beta-$ IP3- $\mathrm{Ca}^{2+}-\mathrm{MLC} 2$ pathway is critically involved in $12(\mathrm{~S})$ HETE-induced CCID formation in CAFs.

\section{ROCK transduces 12(S)-HETE-triggered MLC2 activation and CCID formation}

Next, we addressed how increased cellular $\mathrm{Ca}^{2+}$ levels may induce $\mathrm{CAF}$ retraction. $\mathrm{Ca}^{2+}$ activates $\mathrm{Ca}$-calmodulin kinase II (CamK-II) and specific inhibition of CamK-II by treatment of CAFs with $\mathrm{KN}-62$ significantly attenuated CCID formation (Fig. 4a) and MLC2 phosphorylation (Supplementary Fig. S4). In dendritic cells, CamK-II activates the RHO/ROCK axis, both are regulators of cellular mobility, thereby linking $\mathrm{Ca}^{2+}$ signalling to cell movement [29]. Here we demonstrate that this was also the case in CT5.3 fibroblasts, as treatment with the ROCKinhibitor Y27632 attenuated 12(S)-HETE-induced MLC2 phosphorylation at Ser19 (Fig. 4b). Furthermore, CRCtriggered CCID formation was inhibited by Y27632 in CT5.3 (Fig. 4c) and CAF3 (Fig. 4d) and by the RHO inhibitor rhosin (Fig. 4e, f) in a dose-dependent manner, which inhibited MLC2 phosphorylation (Supplementary Fig. S4) as well. Therefore, the CamK-II/RHO/ROCK/ MLC2 pathway transduces the 12(S)-HETE signal in CAFs, leading to retraction and opening the gate for tumour invasion in vitro.

Interestingly, 12(S)-HETE-induced increase in free intracellular $\mathrm{Ca}^{2+}$ levels was inhibited by rhosin (Fig. 4g), suggesting that RHO transduced signals not only downstream of CamK-II but also upstream of $\mathrm{Ca}^{2+}$ release thereby representing a kind of feedback loop. CamK-II was reported to activate RHO [30, 31] and RHO induces PLCepsilon, $\mathrm{Ca}^{2+}$ release, and cytoskeleton modifications $[32,33]$. Consistently, the inhibition of RHO together with the inhibition of $\mathrm{Ca}^{2+}$ release attenuated CCID formation additively (Fig. 4h). Another $\mathrm{Ca}^{2+}$-calmodulin kinase subtype, MYLK which activates MLC2 directly [34], contributed to CCID formation as well. This was demonstrated by siRNA-mediated depletion of MYLK in CT5.3 fibroblasts and $\mathrm{CAF} 3$, which attenuated CCID formation (Fig. 4i, j; proper knock-down of MYLK expression is shown in supplementary Fig. S5). Taken together, these data place $\mathrm{Ca}^{2+}$ as a central signal for retraction of CAFs triggered by CRC spheroids.

\section{FDA-approved pharmaceutical drugs inhibit 12(S)- HETE-induced $\mathrm{Ca}^{2+}$ release and $\mathrm{CRC}$ invasion in vitro}

To test the hypothesis that $\mathrm{Ca}^{2+}$ signalling is pivotal for CAF retraction, CT5.3 were pre-treated with FDA-approved drugs that reportedly influence $\mathrm{Ca}^{2+}$ availability by blocking respective ion channels. For this, we used carbamazepine (inhibiting L-type calcium channels), cinnarizine (inhibiting IP3-induced intracellular $\mathrm{Ca}^{2+}$ mobilisation), nifedipine (inhibiting L-type calcium channels specifically on vascular cells) and bepridil hydrochloride (inhibits binding to calmodulin only in the presence of calcium, thereby inhibiting MYLK and MLC2 phosphorylation) [35-38]. Each of these drugs inhibited $\mathrm{Ca}^{2+}$ release (Fig. 5a), as well as phosphorylation of MLC2 (except cinnarizine; Supplementary Fig. S4), and significantly attenuated SW620-mediated CCID formation in CT5.3 (Fig. 5b-e). Of note, in vitro retraction of CAFs was reduced at drug concentrations that can be principally achieved in humans.

\section{Discussion}

Over time, malignant cancer cells acquire pro-invasive properties that are necessary to overcome a number of obstacles posed by the surrounding environment and, as an example, cancer cells reprogram their microenvironment to achieve metastatic outgrowth. In short, metastatic spreading involves remodelling of the basal matrix, local invasion through the adjacent stroma, transmigration into blood and lymph vessels, lymph node metastasis, mastering the shear stress within blood and lymph vessels, extravasation, and organ invasion. All these steps require a close cooperation of the tumour microenvironment. Therefore, understanding and manipulating of even just one of the many metastatic steps may provide a rationale for the prevention and the therapeutic management of metastasis. Yet, studies to delineate the contribution of stromal cells in this process mechanistically are scarce.

Honn and co-workers identified 12(S)-HETE as the "endothelial retraction factor" [6]. Neutrophils and monocytes are known to secrete 12(S)-HETE [5, 39] enabling them to transmigrate through endothelial cell 
a

a Intracellular Calcium Level in CT5.3 cells

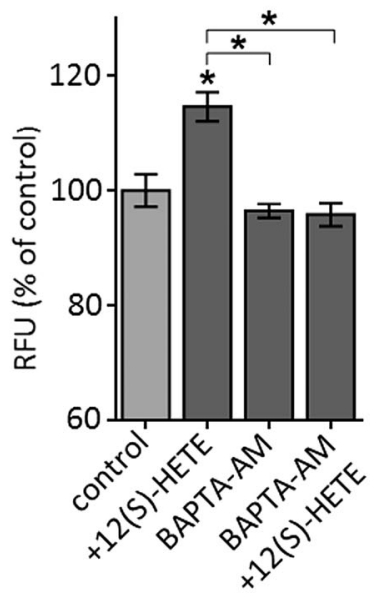

C

SW620 on CT5.3

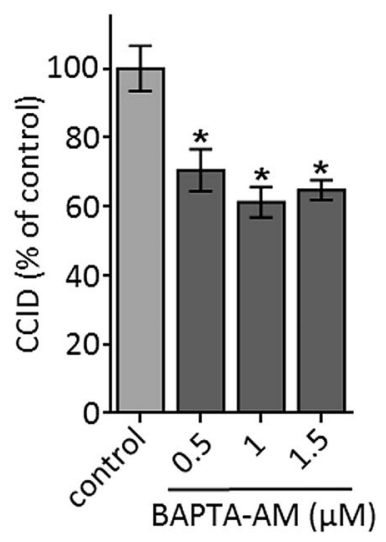

f

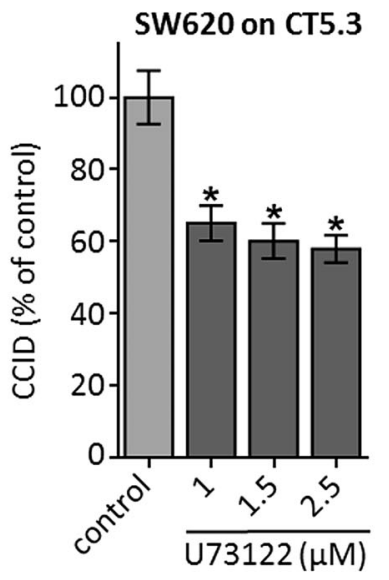

\section{b}

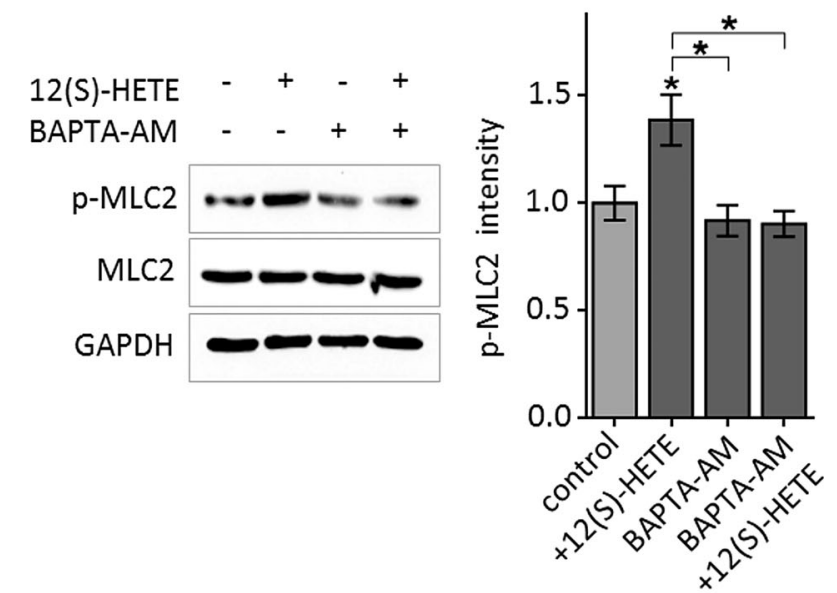

d

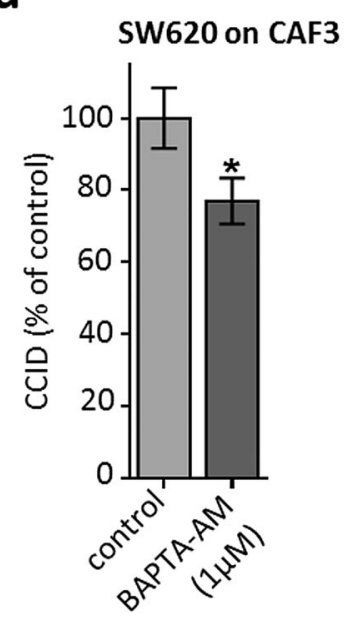

e

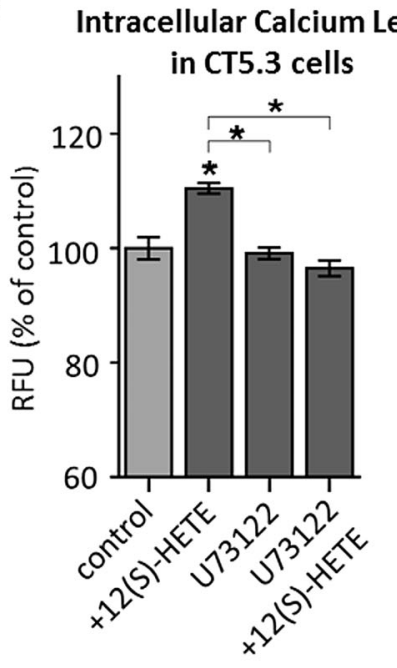

g

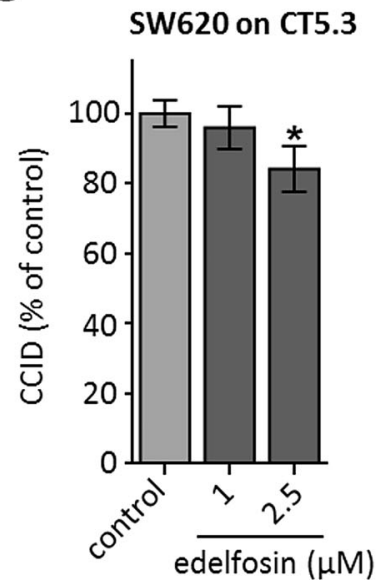


4 Fig. 3 Analysis of the 12(S)-HETE-induced $\mathrm{Ca}^{2+}$ pathway in CT5.3 cells. a CT5.3 were pre-treated with $2.5 \mu \mathrm{M}$ BAPTA-AM, $2.5 \mu \mathrm{M}$ U73122 or DMSO and subsequently incubated with FluoForte ${ }^{\mathrm{TM}}$ Dye. Then, cells were stimulated with $1 \mu \mathrm{M} 12$ (S)-HETE or solvent (control; DMSO) and intracellular-free calcium was measured after 3 min. b CT5.3 were pre-treated with $2.5 \mu \mathrm{M}$ BAPTA-AM or DMSO and stimulated with $1 \mu \mathrm{M}$ 12(S)-HETE or solvent (control; DMSO). After 15-min cells were lysed, proteins separated by SDS gel electrophoresis and analysed by Western blotting was used to determine MLC2 phosphorylation at serine 19. Equal sample loading was controlled by MLC2 total protein and GAPDH. Phospho-MLC2 (p-MLC2) was quantified by densitometry and normalised to MLC2 and GAPDH. Solvent-treated control was set to 1. c-f CAFs were pretreated with the intracellular $\mathrm{Ca}^{2+}$ chelator BAPTA-AM, U73122 (inhibiting the generation of IP3) and the PLC inhibitor edelfosine at indicated concentrations or DMSO (control). Then, SW620 spheroids were placed on top of the CAF monolayers for $6 \mathrm{~h}$ and CCID areas were measured. Bar graphs represent means, error bars indicate \pm SEM, asterisks significance compared to control $(p<0.05 ; t$ test or ANOVA)

(EC) barriers by triggering EC junction retraction. Likewise, MCF-7 breast cancer- [16, 40] and SW620 CRC cells [13] co-opt this mechanism and secrete 12(S)-HETE, which facilitates entering the lymphatic vasculature, travelling through the lymphatic endothelium and colonising lymph nodes. Baicalein is an accepted bona fide inhibitor of ALOX12/15, yet not entirely specific. Thus, the production of 12(S)-HETE by ALOX12/15 and its role for EC junction retraction and CCID formation was not only examined upon treatment with baicalein but also by an approach using shRNA against ALOX15 and the correlation between both inhibition experiments was direct and strict in a breast cancer/EC model [15]. As baicalein inhibited the retraction phenotype also in CRC/EC intravasation models [7, 15], it was also applied in the CRC/CAF model to highlight a role of ALOX12/15 in the invasion of CRC. CYP1A1 is another enzyme that produces 12(S)-HETE. CYP1A1 inhibition by siRNA and proadifen in breast cancer cells [10] or by proadifen in CRC cells [7] reduced the synthesis of 12(S)-HETE and the formation of CCIDs in EC monolayers as well and thus, further supports a role of 12(S)-HETE in the malignancy of CRC. Evidence for the pro-invasive contribution of 12(S)HETE is provided by a CRC in vivo model in which the double amount of ALOX12-overexpressing SW480 cells [secreting four to fivefold more 12(S)-HETE as compared to control cells] [41] were detected in the vicinity of the lung blood vessels after transgrafting them into the rear flank of SCID mice [13]. ECs and CAFs are of mesenchymal origin and therefore quite mobile. 12(S)-HETE even increases their mesenchymal signature, which is reminiscent to "endothelial-to-mesenchymal-transition" (Endo-MT) in ECs [7, 14]. 12(S)-HETE also enhances the invasion of prostate cancer cells [42] potentially involving "epithelial-to-mesenchymal-transition" (EMT). Here, we elucidated the molecular/biochemical and cellular response of CAFs to CRC-derived 12(S)-HETE and demonstrate for the first time that $12(\mathrm{~S})$-HETE forced CAF retraction in vitro, which resulted in the formation of large gaps and upon contact with CRC spheroids both cell types dispersed into each other. It has to be underscored that the molecular adhesion between cancer cells and CAFs is an absolute prerequisite for CCID formation. However, the protagonists of inter-cellular adhesion are not yet identified in the here presented 3D model. Whether NF-kB and ICAM-1 establish CRC-CAF adhesion, as shown to be the case in 12(S)-HETE-triggered breast cancer/EC intravasation $[14,19]$, needs to be investigated in future studies.

We provide mechanistic evidence that the 12(S)-HETEtriggered signal in CAFs was mediated at least in part by the $\mathrm{Ca}^{2+} / \mathrm{RHO} / \mathrm{ROCK}$ signalling axis ultimately leading to MLC2 activation, as all tested signal transduction inhibitors abrogated not only the 12(S)-HETE-induced signalling cascade and MLC2 phosphorylation (except cinnarizine), but also CCID formation. Most importantly, the knockdown of MLC2 inhibited CRC-triggered CCID formation in CAFs as well and this strongly argues for a contribution of 12(S)-HETE in the disintegration of the CAF barrier.

MLC2 expression and activation are the driving components of CAF mobility and cancer cell invasion. Also in ECs 12(S)-HETE activates MLC2, which significantly contributes to CCID formation [24, 43, 44]. Furthermore, it was shown that activated MLC2 in breast cancer cells accelerates their movement through the underlying endothelium [45]. Hence, during tumour progression, MLC2 seems to play a critical role in cancer cells and adjacent stromal cells. This is in accordance with the observation that tumour cell invasion is supported by the increased mobility of all involved cell types, which start to merge and mingle. However, the induction of MLC2 phosphorylation and CCID formation is not exclusively caused by the $12(\mathrm{~S})$-HETE gradient, as there are also other factors prompting tropism and retraction i.e. MMP1, which induces $\mathrm{Ca}^{2+}$ release and MLC2 activation in ECs as well $[19,46]$. Yet, treating the CRC/CAF model with the panmatrix metalloprotease inhibitor GM6001 did not inhibit the formation of CCIDs (data not shown). Therefore, this mechanism, which is known to contribute significantly in breast cancer/EC models, was not active during invasion of CRC into the CAF compartment.

$\mathrm{Ca}^{2+}$ availability and release are crucial steps in mediating retraction and mobility. Consistently, chelation of $\mathrm{Ca}^{2+}$ (by BAPTA-AM) together with simultaneous inhibition of RHO (by rhosin) impaired CCID formation within the CAF barrier, probably due to blocking the positive feed-back loop of RHO on $\mathrm{Ca}^{2+}$ release. Alternatively, the reduced CCID formation may have been due to simultaneous blocking of MYLK (another $\mathrm{Ca}^{2+}$-calmodulin kinase 
a

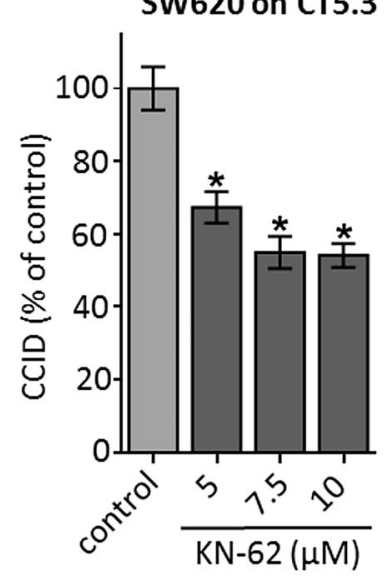

C

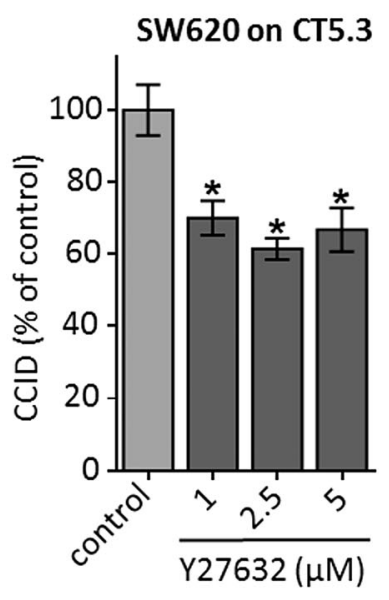

b

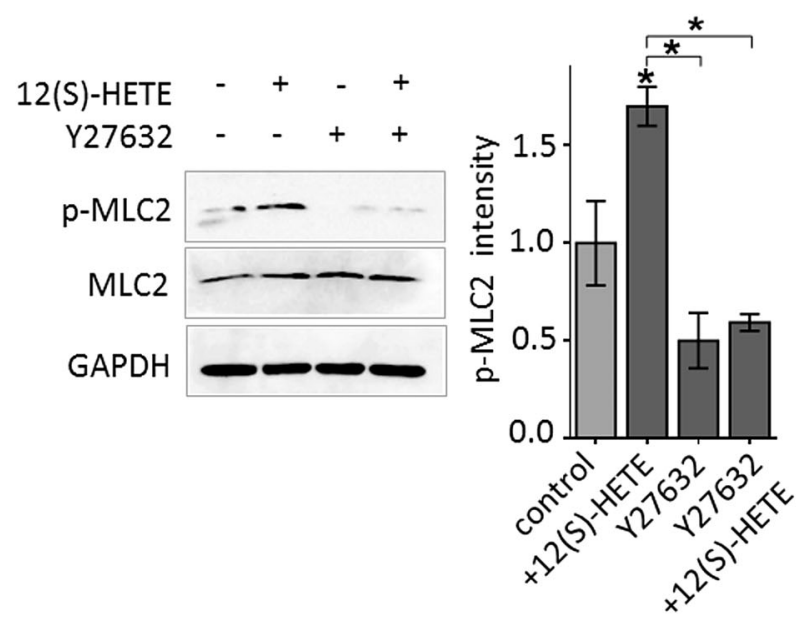

d

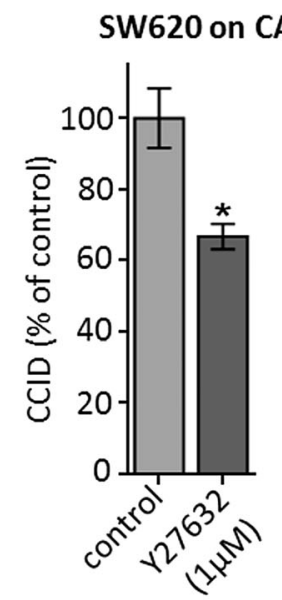

e
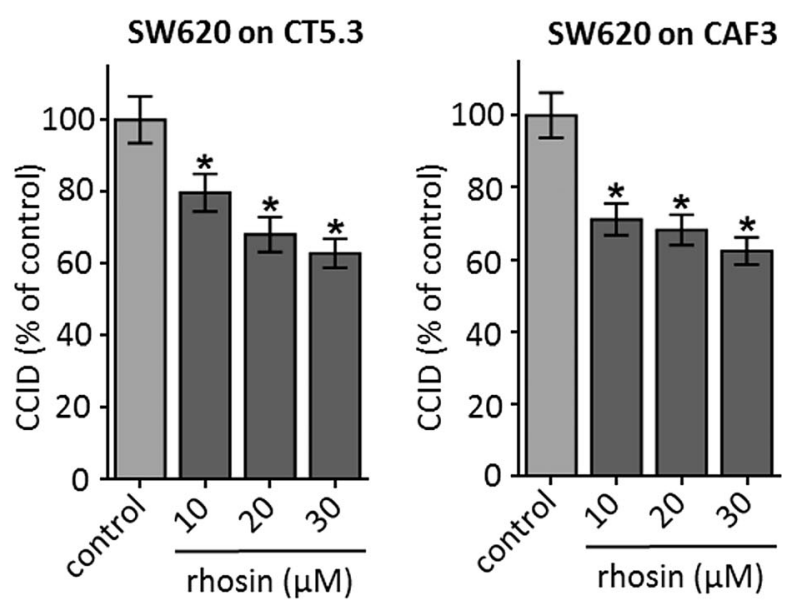
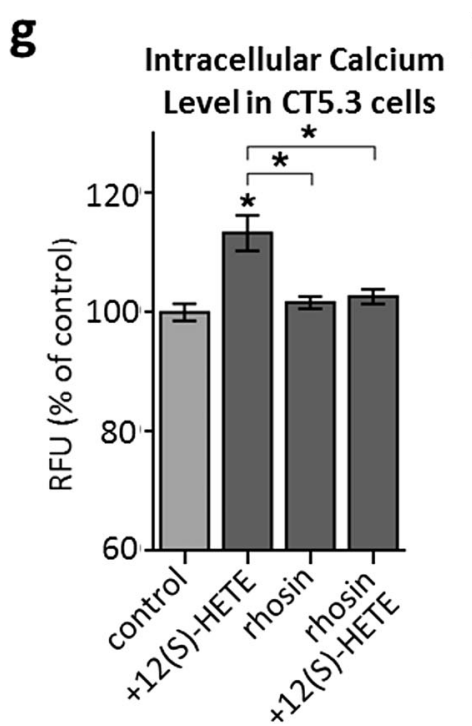

$h$

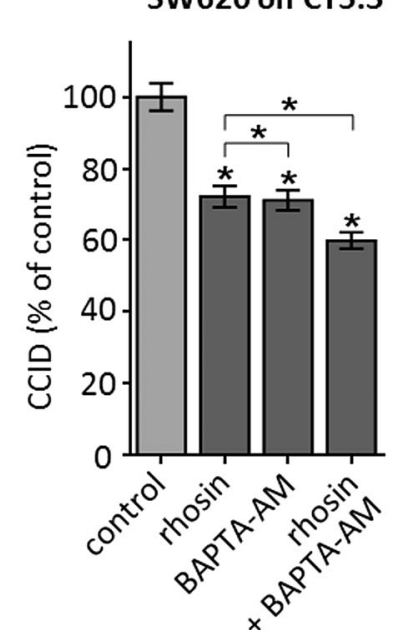

i SW620 on CT5.3

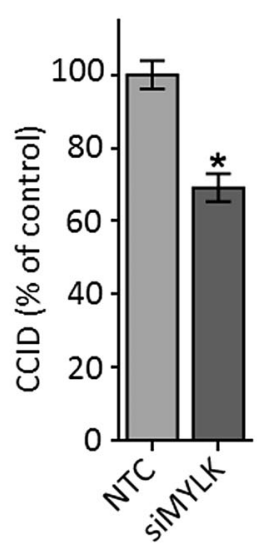

j

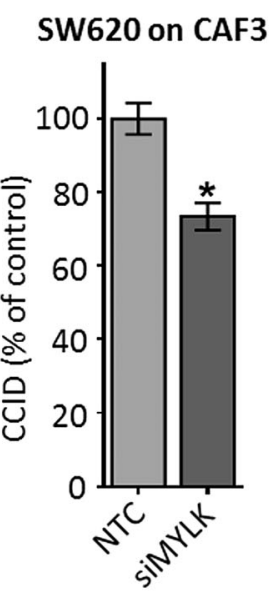


4Fig. $4 \mathrm{RHO} / \mathrm{ROCK}$ signalling is involved in CAF retraction. a CT5.3 were pre-treated with the CamK-II inhibitor $\mathrm{KN}-62$ at indicated concentrations or solvent as control (control; DMSO). Subsequently, SW620 spheroids were placed on top of the fibroblasts for $6 \mathrm{~h}$ CCID areas were measured. b Cells were pre-treated with $2.5 \mu \mathrm{M}$ of the ROCK inhibitor Y27632 or solvent and subsequently stimulated with $1 \mu \mathrm{M}$ 12(S)-HETE or solvent (control; DMSO) for $15 \mathrm{~min}$. Western blotting was used to determine MLC2 phosphorylation at serine 19. Equal sample loading was controlled by MLC2 total protein and GAPDH. Phospho-MLC2 (p-MLC2) was quantified by densitometry and normalised to MLC2 and GAPDH. Solvent treated control was set to 1 . c-f CT5.3 and CAF3 were pre-treated with Y27632 and the RHO inhibitor rhosin at indicated concentrations or solvent as control (control; DMSO). Subsequently, SW620 spheroids were placed on top of the fibroblasts for $6 \mathrm{~h} \mathrm{CCID} \mathrm{areas} \mathrm{were} \mathrm{measured.} \mathrm{g} \mathrm{CT5.3}$ were pre-treated with $20 \mu \mathrm{M}$ rhosin or DMSO, stimulated with $1 \mu \mathrm{M}$ 12(S)-HETE or solvent (control; DMSO) and intracellular-free calcium was measured after $3 \mathrm{~min}$. h CT5.3 cells were pre-treated with $20 \mu \mathrm{M}$ rhosin, $1 \mu \mathrm{M}$ BAPTA-AM or both and solvent (DMSO) was used as control (control). Then, SW620 spheroids were placed on top of CT5.3 for $6 \mathrm{~h}$ and CCID areas were measured. i, j CT5.3 and CAF3 were transfected with either non-targeting RNA (NTC) or siRNA targeting MYLK (siMYLK). After $24 \mathrm{~h}$ SW620 spheroids were transferred on top of the CT5.3 monolayers and after $6 \mathrm{~h}$ cocultivation CCID areas were measured. Error bars indicate mean \pm SEM, asterisks significance compared to control or compared to the experimental points connected by brackets $(p<0.05$; $t$ test or ANOVA)

subtype directly activating MLC2) [34] together with the inhibition of RHO. MYLK is strongly expressed in CAFs as well as in IMR-90 normal lung fibroblasts (https://www. ebi.ac.uk/gxa/home) and we could demonstrate that primary normal human lung fibroblasts (HLF) respond in a similar way to SW620 spheroids as CAFs. Nearly as strong as MYLK is the expression of CamK-IId in IMR-90 fibroblasts, whereas the expression of CamK-IIg, CamK-I and CamK-III (EEF2K) is low (https://www.ebi.ac.uk/gxa/ home; E-GEOD-26284; EMBL-EBI Expression Atlas, which contains gene expression data based on RNA sequencing). Hence, all of these CamKs may have contributed to the 12(S)-HETE-triggered and $\mathrm{Ca}^{2+}$-mediated fibroblast response that resulted in MLC2 phosphorylation and CCID formation. In line with the central role of elevated $\mathrm{Ca}^{2+}$ levels in response to 12(S)-HETE, we demonstrate that clinically used drugs, which were chosen on their property to affect calcium supply, inhibited the invasion of CRC spheroids through the CAF barrier. Of note, the here tested FDA-approved drugs diminished CAF retraction at concentrations that can be reached in humans. Therefore, it is tempting to speculate that interfering with $\mathrm{Ca}^{2+}$ availability might be a broadly applicable and promising route to combat metastasis in the clinic. This could be achieved in a short time frame, since such inhibitors are already approved and in use. However, one a

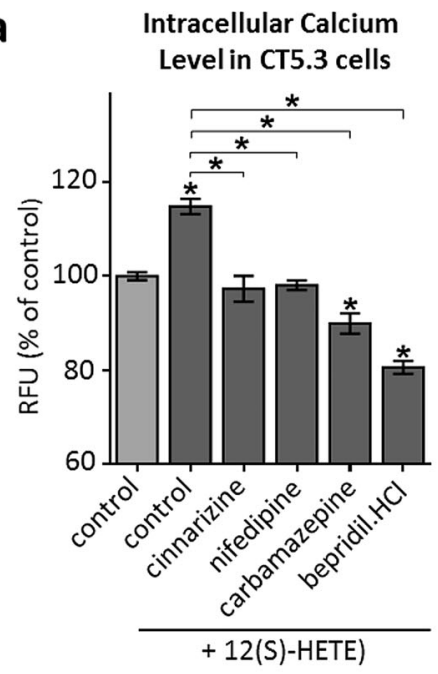

b

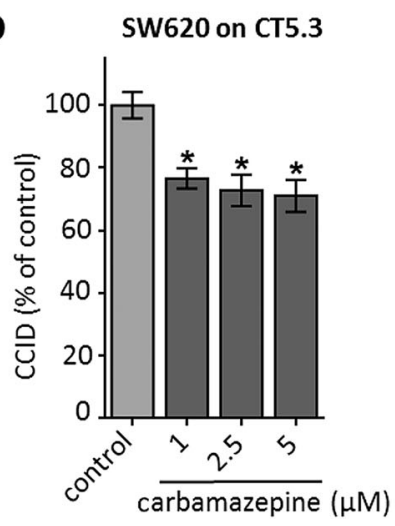

C

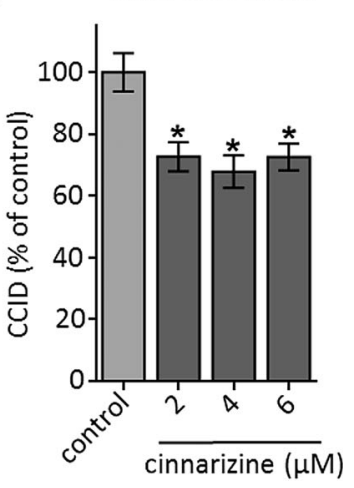

d

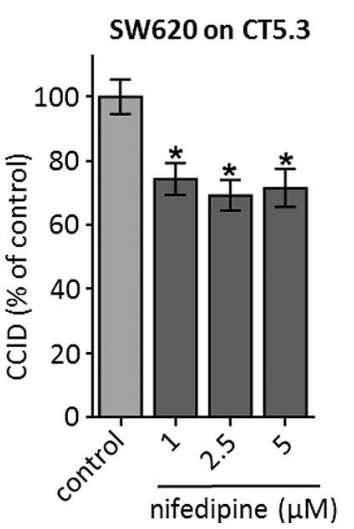

e

SW620 on CT5.3

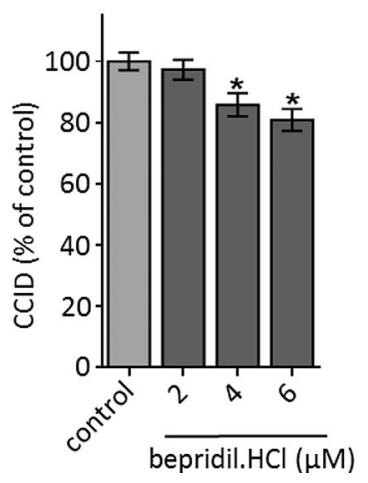

Fig. 5 Inhibition of intracellular $\mathrm{Ca}^{2+}$ level increase and CCID formation by FDA-approved drugs. a CT5.3 were pre-treated with either carbamazepine, cinnarizine, nifedipine, bepridil hydrochloride or DMSO, stimulated with $1 \mu \mathrm{M} 12$ (S)-HETE or solvent (control; DMSO) and intracellular-free calcium was measured after $3 \mathrm{~min}$. be CT5. 3 cells were pre-treated with either carbamazepine, cinnarizine, nifedipine and bepridil hydrochloride at indicated concentrations or solvent (control; DMSO). Then, SW620 spheroids were placed on top of the CT5.3 for $6 \mathrm{~h}$ and CCID areas were measured. Bar graphs represent means, error bars indicate \pm SEM, asterisks significance compared to control ( $p<0.05 ; t$ test or ANOVA) 
should have in mind that cancer cells may co-opt any mechanism (not just the one described herein) that has evolved to disintegrate, repulse and penetrate foreign tissue types.

Acknowledgements Open access funding provided by Medical University of Vienna. We wish to thank Toni Jäger for preparing the figures. The work was supported by a grant of the Herzfeldersche Family Foundation to G.K. C.H.N was supported by technology grant (TSA Doktorat) financed by the Austria Federal Ministry of Science and Research (BMFW) in frame of Asea Uninet.

\section{Compliance with ethical standards}

Ethical standards Surgical specimens were collected from 3 patients who underwent surgery for colorectal cancer and gave their informed consent. The study protocol was approved by the ethics committee of the Medical University of Vienna (EK 1659/2012).

Conflict of interest The authors declare no conflict of interest.

Open Access This article is distributed under the terms of the Creative Commons Attribution 4.0 International License (http:// creativecommons.org/licenses/by/4.0/), which permits unrestricted use, distribution, and reproduction in any medium, provided you give appropriate credit to the original author(s) and the source, provide a link to the Creative Commons license, and indicate if changes were made.

\section{References}

1. Vogelstein B, Kinzler KW (2004) Cancer genes and the pathways they control. Nat Med 10:789-799

2. Hanahan D, Weinberg RA (2011) Hallmarks of cancer: the next generation. Cell 144:646-674

3. Calon A, Lonardo E, Berenguer-Llergo A, Espinet E, HernandoMomblona X, Iglesias M, Sevillano M, Palomo-Ponce S, Tauriello DV, Byrom D, Cortina C, Morral C, Barceló C, Tosi S, Riera A, Attolini CS, Rossell D, Sancho E, Batlle E (2015) Stromal gene expression defines poor-prognosis subtypes in colorectal cancer. Nat Genet 47:320-329

4. Isella C, Terrasi A, Bellomo SE, Petti C, Galatola G, Muratore A, Mellano A, Senetta R, Cassenti A, Sonetto C, Inghirami G, Trusolino L, Fekete Z, De Ridder M, Cassoni P, Storme G, Bertotti A, Medico E (2015) Stromal contribution to the colorectal cancer transcriptome. Nat Genet 47:312-319

5. Rigby DA, Ferguson DJ, Johnson LA, Jackson DG (2015) Neutrophils rapidly transit inflamed lymphatic vessel endothelium via integrin-dependent proteolysis and lipoxin-induced junctional retraction. J Leukoc Biol 98:897-912

6. Honn KV, Tang DG, Grossi I, Duniec ZM, Timar J, Renaud C, Leithauser M, Blair I, Johnson CR, Diglio CA, Kimler VA, Taylor JD, Marnett LJ (1994) Tumor cell-derived 12(S)-hydroxyeicosatetraenoic acid induces microvascular endothelial cell retraction. Cancer Res 54:565-574

7. Senfter D, Holzner S, Kalipciyan M, Staribacher A, Walzl A, Huttary N, Krieger S, Brenner S, Jäger W, Krupitza G, Dolznig H, Mader RM (2015) Loss of miR-200 family in 5-fluorouracil resistant colon cancer drives lymphendothelial invasiveness in vitro. Hum Mol Genet 24:3689-3698

8. Funk CD (1996) The molecular biology of mammalian lipoxygenases and the quest for eicosanoid functions using lipoxygenase-deficient mice. Biochim Biophys Acta 1304:65-84
9. El-Sherbeni AA, El-Kadi AO (2016) Repurposing resveratrol and fluconazole to modulate human cytochrome P450-mediated arachidonic acid metabolism. Mol Pharm 13:1278-1288

10. Nguyen CH, Brenner S, Huttary N, Atanasov AG, Dirsch VM, Chatuphonprasert W, Holzner S, Stadler S, Riha J, Krieger S, de Martin R, Bago-Horvath Z, Krupitza G, Jäger W (2016) AHR/ CYP1A1 interplay triggers lymphatic barrier breaching in breast cancer spheroids by inducing 12(S)-HETE synthesis. Hum Mol Genet (Epub ahead of print)

11. Timar J, Raso E, Fazakas ZS, Silletti S, Raz A, Honn KV (1996) Multiple use of a signal transduction pathway in tumor cell invasion. Anticancer Res 16:3299-3306

12. Shureiqi I, Chen D, Day RS, Zuo X, Hochman FL, Ross WA, Cole RA, Moy O, Morris JS, Xiao L, Newman RA, Yang P, Lippman SM (2010) Profiling lipoxygenase metabolism in specific steps of colorectal tumorigenesis. Cancer Prev Res 3:829-838

13. Klampfl T, Bogner E, Bednar W, Mager L, Massudom D, Kalny I, Heinzle C, Berger W, Stättner S, Karner J, Klimpfinger M, Fürstenberger G, Krieg P, Marian B (2012) Up-regulation of 12(S)-lipoxygenase induces a migratory phenotype in colorectal cancer cells. Exp Cell Res 318:768-778

14. Vonach C, Viola K, Giessrigl B, Huttary N, Raab I, Kalt R, Krieger S, Vo TP, Madlener S, Bauer S, Marian B, Hämmerle M, Kretschy N, Teichmann M, Hantusch B, Stary S, Unger C, Seelinger M, Eger A, Mader R, Jäger W, Schmidt W, Grusch M, Dolznig H, Mikulits W, Krupitza G (2011) NF- $\kappa B$ mediates the 12(S)-HETE-induced endothelial to mesenchymal transition of lymphendothelial cells during the intravasation of breast carcinoma cells. Br J Cancer 105:263-271

15. Kerjaschki D, Bago-Horvath Z, Rudas M, Sexl V, Schneckenleithner C, Wolbank S, Bartel G, Krieger S, Kalt R, Hantusch B, Keller T, Nagy-Bojarszky K, Huttary N, Raab I, Lackner K, Krautgasser K, Schachner H, Kaserer K, Rezar S, Madlener S, Vonach C, Davidovits A, Nosaka H, Hämmerle M, Viola K, Dolznig H, Schreiber M, Nader A, Mikulits W, Gnant M, Hirakawa S, Detmar M, Alitalo K, Nijman S, Offner F, Maier TJ, Steinhilber D, Krupitza G (2011) Lipoxygenase mediates invasion of intrametastatic lymphatic vessels and propagates lymph node metastasis of human mammary carcinoma xenografts in mouse. J Clin Invest 121:2000-2012

16. Rabinovitch H, Durand J, Rigaud M, Mendy F, Breton JC (1981) Transformation of arachidonic acid into monohydroxy-eicosatetraenoic acids by mouse peritoneal macrophages. Lipids 16:518-524

17. Madlener S, Saiko P, Vonach C, Viola K, Huttary N, Stark N, Popescu R, Gridling M, Vo NT, Herbacek I, Davidovits A, Giessrigl B, Venkateswarlu S, Geleff S, Jäger W, Grusch M, Kerjaschki D, Mikulits W, Golakoti T, Fritzer-Szekeres M, Szekeres T, Krupitza G (2010) Multifactorial anticancer effects of digalloyl-resveratrol encompass apoptosis, cell-cycle arrest, and inhibition of lymphendothelial gap formation in vitro. $\mathrm{Br} \mathbf{J}$ Cancer 102:1361-1370

18. Viola K, Kopf S, Huttary N, Vonach C, Kretschy N, Teichmann M, Giessrigl B, Raab I, Stary S, Krieger S, Keller T, Bauer S, Hantusch B, Szekeres T, de Martin R, Jäger W, Mikulits W, Dolznig H, Krupitza G, Grusch M (2013) Bay11-7082 inhibits the disintegration of the lymphendothelial barrier triggered by MCF-7 breast cancer spheroids; the role of ICAM- 1 and adhesion. Br J Cancer 108:564-569

19. Nguyen CH, Senfter D, Basilio J, Holzner S, Stadler S, Krieger S, Huttary N, Milovanovic D, Viola K, Simonitsch-Klupp I, Jäger W, de Martin R, Krupitza G (2015) NF- $\kappa B$ contributes to MMP1 expression in breast cancer spheroids causing paracrine PAR1 activation and disintegrations in the lymph endothelial barrier in vitro. Oncotarget 6:39262-39275 
20. Richter M, Jurek D, Wrba F, Kaserer K, Wurzer G, KarnerHanusch J, Marian B (2002) Cells obtained from colorectal microadenomas mirror early premalignant growth patterns in vitro. Eur J Cancer 38:1937-1945

21. De Vlieghere E, Gremonprez F, Verset L, Mariën L, Jones CJ, De Craene B, Berx G, Descamps B, Vanhove C, Remon JP, Ceelen W, Demetter P, Bracke M, De Geest BG, De Wever O (2015) Tumor-environment biomimetics delay peritoneal metastasis formation by deceiving and redirecting disseminated cancer cells. Biomaterials 54:148-157

22. Dolznig H, Rupp C, Puri C, Haslinger C, Schweifer N, Wieser E, Kerjaschki D, Garin-Chesa P (2011) Modeling colon adenocarcinomas in vitro a 3D co-culture system induces cancer-relevant pathways upon tumor cell and stromal fibroblast interaction. Am J Pathol 179:487-501

23. Teichmann M, Kretschy N, Kopf S, Jarukamjorn K, Atanasov AG, Viola K, Giessrigl B, Saiko P, Szekeres T, Mikulits W, Dirsch VM, Huttary N, Krieger S, Jäger W, Grusch M, Dolznig H, Krupitza G (2014) Inhibition of tumour spheroid-induced prometastatic intravasation gates in the lymph endothelial cell barrier by carbamazepine: drug testing in a 3D model. Arch Toxicol 88:691-699

24. Nguyen CH, Stadler S, Brenner S, Huttary N, Krieger S, Jäger W, Dolznig H, Krupitza G (2016) Cancer cell derived 12(S)-HETE signals via 12-HETE receptor, RHO, ROCK and MLC2 to induce lymph endothelial barrier breaching. Br J Cancer. doi:10.1038/ bjc. 2016.201

25. Ueki S, Takagi J, Kobayashi Y, Sato F, Saito Y (1999) 12-hydroxy-5Z, 8Z, 10E, 14Z, eicosatetraenoic acid (12-HETE) stimulates cAMP production in normal human fibroblasts. J Cell Physiol 178:63-68

26. Hasegawa G, Kumagai S, Yano M, Wang YG, Kobayashi Y, Saito Y (2003) 12(S)-Hydroxyeicosatetraenoic acid induces cAMP production via increasing intracellular calcium concentration. FEBS Lett 554:127-132

27. Yokomizo T, Kato K, Hagiya H, Izumi T, Shimizu T (2001) Hydroxyeicosanoids bind to and activate the low affinity leukotriene B4 receptor, BLT2. J Biol Chem 276:12454-12459

28. Yiu SS, Zhao X, Inscho EW, Imig JD (2003) 12-Hydroxyeicosatetraenoic acid participates in angiotensin II afferent arteriolar vasoconstriction by activating L-type calcium channels. J Lipid Res 44:2391-2399

29. Murakoshi H, Hong Wang H, Yasuda R (2011) Local, persistent activation of Rho GTPases during plasticity of single dendritic spines. Nature 472:100-104

30. Seifert JP, Wing MR, Snyder JT, Gershburg S, Sondek J, Harden TK (2004) RhoA activates purified phospholipase C-epsilon by a guanine nucleotide-dependent mechanism. J Biol Chem 279:47992-47997

31. Seifert JP, Zhou Y, Hicks SN, Sondek J, Harden TK (2008) Dual activation of phospholipase C-epsilon by Rho and Ras GTPases. J Biol Chem 283:29690-29698

32. Bourguignon LY, Gilad E, Brightman A, Diedrich F, Singleton P (2006) Hyaluronan-CD44 interaction with leukemia-associated RhoGEF and epidermal growth factor receptor promotes Rho/Ras co-activation, phospholipase $\mathrm{C}$ epsilon- $\mathrm{Ca}^{2+}$ signaling, and cytoskeleton modification in head and neck squamous cell carcinoma cells. J Biol Chem 281:14026-41400

33. Oestreich EA, Malik S, Goonasekera SA, Blaxall BC, Kelley GG, Dirksen RT, Smrcka AV (2009) Epac and phospholipase Cepsilon regulate $\mathrm{Ca}^{2+}$ release in the heart by activation of protein kinase Cepsilon and calcium-calmodulin kinase II. J Biol Chem 284:1514-1522
34. Shen Q, Rigor RR, Pivetti CD, Wu MH, Yuan SY (2010) Myosin light chain kinase in microvascular endothelial barrier function. Cardiovasc Res 87:272-280

35. Du T, Liang C, Li B, Hertz L, Peng L (2014) Chronic fluoxetine administration increases expression of the L-channel gene Cav1.2 in astrocytes from the brain of treated mice and in culture and augments $\mathrm{K}(+)$-induced increase in $[\mathrm{Ca}(2+)] i$. Cell Calcium 55:166-174

36. Ohtsuki H, Morita K, Minami N, Suemitsu T, Tsujimoto A, Dohi $\mathrm{T}$ (1992) Involvement of $\mathrm{Ca}^{2+}$ entry and inositol trisphosphateinduced internal $\mathrm{Ca}^{2+}$ mobilization in muscarinic receptor-mediated catecholamine release in dog adrenal chromaffin cells. Neurochem Int 21:259-267

37. Little WC, Cheng CP (1994) Vascular versus myocardial effects of calcium antagonists. Drugs 47(Suppl 4):41-46

38. Itoh H, Tanaka T, Mitani Y, Hidaka H (1986) The binding of the calcium channel blocker, bepridil, to calmodulin. Biochem Pharmacol 35:217-220

39. Bolick DT, Orr AW, Whetzel A, Srinivasan S, Hatley ME, Schwartz MA, Hedrick CC (2005) 12/15-Lipoxygenase regulates intercellular adhesion molecule-1 expression and monocyte adhesion to endothelium through activation of RhoA and nuclear factor-kappaB. Arterioscler Thromb Vasc Biol 25:2301-2307

40. Uchide K, Sakon M, Ariyoshi H, Nakamori S, Tokunaga M, Monden M (2007) Cancer cells cause vascular endothelial cell (vEC) retraction via 12(S)HETE secretion; the possible role of cancer cell derived microparticle. Ann Surg Oncol 14:862-868

41. Bednar W, Holzmann K, Marian B (2007) Assessing 12(S)lipoxygenase inhibitory activity using colorectal cancer cells overexpressing the enzyme. Food Chem Toxicol 45:508-514

42. Guo Y, Zhang W, Giroux C, Cai Y, Ekambaram P, Dilly AK, Hsu A, Zhou S, Maddipati KR, Liu J, Joshi S, Tucker SC, Lee MJ, Honn KV (2011) Identification of the orphan G protein-coupled receptor GPR31 as a receptor for 12-(S)-hydroxyeicosatetraenoic acid. J Biol Chem 286:33832-33840

43. Kretschy N, Teichmann M, Kopf S, Atanasov AG, Saiko P, Vonach C, Viola K, Giessrigl B, Huttary N, Raab I, Krieger S, Jäger W, Szekeres T, Nijman SM, Mikulits W, Dirsch VM, Dolznig H, Grusch M, Krupitza G (2013) In vitro inhibition of breast cancer spheroid-induced lymphendothelial defects resembling intravasation into the lymphatic vasculature by acetohexamide, isoxsuprine, nifedipin and proadifen. Br J Cancer 108:570-578

44. Nguyen CH, Brenner S, Huttary N, Li Y, Atanasov AG, Dirsch VM, Holzner S, Stadler S, Riha J, Krieger S, Milovanovic D, Fristiohardy A, Simonitsch-Klupp I, Dolznig H, Saiko P, Szekeres T, Giessrigl B, Jäger W, Krupitza G (2016) 12(S)-HETE increases intracellular $\mathrm{Ca}^{2+}$ in lymph-endothelial cells disrupting their barrier function in vitro; stabilisation by clinical drugs impairing calcium supply. Cancer Lett. doi:10.1016/j.canlet. 2016.06.022

45. Khuon S, Liang L, Dettman RW, Sporn PHS, Wysolmerski RB, Chew TL (2010) Myosin light chain kinase mediates transcellular intravasation of breast cancer cells through the underlying endothelial cells: a three-dimensional FRET study. J Cell Sci 123:431-440

46. Juncker-Jensen A, Deryugina EI, Rimann I, Zajac E, Kupriyanova TA, Engelholm LH, Quigley JP (2013) Tumor MMP-1 activates endothelial PAR1 to facilitate vascular intravasation and metastatic dissemination. Cancer Res 73:4196-4211 